\title{
A DESIGUALDADE SENTIDA NA MIGRAÇÃO DE ESTUDANTES UNIVERSITÁRIOS PROVENIENTES DO CONTINENTE AFRICANO
}

\author{
LA DESIGUALDAD QUE SE SIENTE EN LA MIGRACIÓN DE ESTUDIANTES \\ UNIVERSITARIOS DEL CONTINENTE AFRICANO
}

\author{
THE INEQUALITY EXPERIENCED IN THE MIGRATION OF UNIVERSITY \\ STUDENTS OF THE AFRICAN CONTINENT
}

\author{
Denise Miranda de FIGUEIREDO ${ }^{1}$ \\ Ana Lucia de Moraes HORTA ${ }^{2}$ \\ Rosa Maria Stefanini de MACEDO $^{3}$
}

RESUMO: Os fluxos migratórios estão presentes há muitas décadas e possuem relação com processos sociais, culturais e territoriais. O presente artigo analisou, a partir do discurso de estudantes provenientes do continente africano matriculados em instituições de Ensino Superior, as desigualdades sentidas durante o processo deslocamento, ampliando o olhar frente ao fenômeno da migração internacional temporária e elaborando os significados atribuídos as experiências desses indivíduos. O conteúdo dos discursos foi dividido em três temas: a experiência no Brasil, o preconceito vivido e as marcas da migração. Ao longo do estudo ficou explícito que esses fatores atravessaram a vida desses jovens e permearam suas permanências dentro das universidades brasileiras, sendo eles indicadores de como a diversidade vem sendo tratada por nossa sociedade atualmente. Ficou evidente a necessidade de as Universidades possuírem melhor preparo na recepção e ambientação desses alunos, a fim de minimizar as desigualdades de oportunidades, aumentando as possibilidades de um diálogo intercultural.

PALAVRAS-CHAVE: Migração. Estudantes africanos. Psicologia. Desigualdade. Universidade.

RESUMEN: Los flujos migratorios están presentes desde hace muchas décadas y están relacionados con procesos sociales, culturales y territoriales. Este artículo analizó, a partir del discurso de estudiantes del continente africano matriculados en instituciones de Educación Superior, las desigualdades sentidas durante el proceso de desplazamiento, ampliando la mirada al fenómeno de la migración internacional temporal y elaborando los significados atribuidos a las vivencias de estos individuos. Los discursos se dividió en tres temas: experiencia en Brasil, prejuicio vivido y huellas de la migración. Estos factores

\footnotetext{
${ }^{1}$ Universidade Federal de São Paulo (UNIFESP), São Paulo - SP - Brasil. Membro do grupo de Estudo e Pesquisa Família e Comunidade (GEPFAC) da Escola Paulista de Enfermagem. ORCID: https://orcid.org/00000001-5805-3832. E-mail: denise@denisefigueiredo.com.br

${ }^{2}$ Universidade Federal de São Paulo (UNIFESP), São Paulo - SP - Brasil. Chefe do Departamento de Saúde Coletiva da UNIFESP/EPE. Doutorado em Enfermagem (USP). ORCID: https://orcid.org/0000-0002-05143882. E-mail: ana.horta@unifesp.br

${ }^{3}$ Pontifícia Universidade Católica de São Paulo (PUC), São Paulo - SP - Brasil. Coordenadora do Núcleo de Família e Comunidade do Programa de Pós-Graduação em Psicologia Clínica. Doutorado em Psicologia Clínica (PUC). ORCID: https://orcid.org/0000-0001-9771-2845. E-mail: macedo@pucsp.br
} 
atravesaron la vida de estos jóvenes y permearon su permanencia en las universidades brasileñas, que indican cómo la diversidad há sido tratada por nuestra sociedad hoy. Se hizo evidente la necesidad de que las Universidades tengan una mejor preparación para la acogida y ambientación de estos estudiantes con el fin de minimizar las desigualdades en las oportunidades, aumentando las posibilidades de un diálogo intercultural.

PALABRAS CLAVE: Migración. Estudiantes africanos. Psicología. Desigualdad. Universidad.

ABSTRACT: Migration flows have been present for many decades and are related to social, cultural, and territorial processes. This article analyzed, based on the discourse of students from the African continent enrolled in Higher Education institutions, the inequalities felt during the displacement process, expanding the look at the phenomenon of temporary international migration, and elaborating the meanings attributed to the experiences of these individuals. The speeches were divided into three themes: experience in Brazil, prejudice experienced and marks of migration. Throughout the study, it became clear that these factors crossed the lives of these young people and permeated their permanence within Brazilian universities, which are indicators of how diversity has been treated by our society today. It became evident the need for universities to have better preparation for the reception and setting of these students in order to minimize inequalities in opportunities, increasing the possibilities for an intercultural dialogue.

KEYWORDS: Migration. African students. Psychology. Inequality. University.

\section{Introdução}

Os fluxos migratórios fazem parte de nossa sociedade há muitas décadas. Estes estão relacionados a processos sociais de dominação, de invasão, de mercado e de conquistas territoriais. O crescente índice de fluxos migratórios, atualmente, possui relação direta com as histórias de colonização e desenvolvimento dos países, com as desigualdades econômicas mundiais e com os conflitos políticos/étnicos (BADI, 2015). Fatores como: os deslocamentos por motivações econômicas; os índices de desemprego em diferentes zonas urbanas; a escassez de recursos naturais; a vinda de intelectuais e profissionais bem qualificados nas mais diversas áreas, que buscam melhores condições de vida em outros países, regiões ou continentes; e a insuficiência no acesso à qualificação profissional contribui para os movimentos migratórios na atualidade, especialmente para a emigração africana, levando jovens a se deslocarem em busca de formação universitária (BARRETO; COUTINHO; RIBEIRO, 2009).

O presente estudo teve como objetivo analisar, a partir dos principais discursos obtidos na tese de doutorado defendida no Programa de Estudos Pós-graduados em Psicologia Clínica 
da Pontifícia Universidade Católica de São Paulo intitulada "Diálogos interculturais dentro de uma Universidade Brasileira" (FIGUEIREDO, 2013), as desigualdades sentidas durante as experiências singulares de deslocamento de estudantes universitários matriculados em instituições de Ensino Superior, provenientes de diferentes regiões do Continente Africano, ampliando o olhar frente ao fenômeno da migração internacional temporária e elaborando os significados atribuídos a esta experiência desses indivíduos. Para isso, o presente artigo utilizou uma abordagem qualitativa teórico-bibliográfica a fim de analisar, a partir do discurso dos estudantes, experiências de diversos jovens provenientes de países africanos dentro de uma universidade brasileira e apontar as dificuldades por eles enfrentadas para sua adaptação, desde o planejamento para seu acolhimento no país até as relações com professores e colegas. Além disso, foi abordado o tema do preconceito aberto ou velado, presente tanto nas relações com brasileiros, como entre grupos africanos. Para a coleta de informações, foram realizadas entrevistas semiestruturadas com seis estudantes que vivenciaram a migração internacional temporária, que estavam cursando a graduação na Pontifícia Universidade Católica de São Paulo. Dessa forma, os assuntos levantados foram divididos em categorias que serão relacionadas e discutidas a seguir.

\section{O Brasil noticiado e o Brasil experimentado}

Em 1965 foi lançado o primeiro Protocolo Programa Estudante de Convênio de Graduação (PEC-G), de acordo com o Ministério das Relações Exteriores, a ideia da criação de um Programa de Governo para amparar estudantes de outros países adveio do incremento do número de estrangeiros no Brasil, na década de 1960, e das consequências que isso trouxe para a regulamentação interna do status desses estudantes no Brasil. A África é o continente de origem da maior parte dos estudantes, ao longo da última década, foram mais de 6.000 estudantes selecionados pelo Programa. Entre as nações africanas participantes, destacam-se Cabo Verde, Guiné-Bissau e Angola. De acordo com o Ministério das Relações Exteriores, hoje o Brasil conta com aproximadamente 17.000 estudantes estrangeiros matriculados em cursos de graduação, abrangendo 176 diferentes nacionalidades.

Segundo o INEP - Instituto Nacional de Estudos e Pesquisas Educacionais Anísio Teixeira Legislação e Documentos (2018), 45,6\% dos alunos estrangeiros que frequentam cursos de graduação no Brasil, provêm do continente Africano, sendo a Angola, o país com o maior número de alunos estrangeiros. Segundo Amaral (2013), o jovem africano/a vem para o Brasil, em uma quantidade cada vez maior, com o intuito de realizar estudos universitários. 
As oportunidades oferecidas abrangem tanto o ensino superior público, quanto o privado. São ofertadas vagas gratuitas em cursos de graduação nas Instituições de Ensino Superior, da UNILAB (Universidade da Integração da Lusofonia Afro-Brasileira) e dos programas Estudante Convênio de Graduação (PEC-G) e Estudante Convênio de Pós-graduação (PECPG), destinadas à formação e qualificação de estudantes estrangeiros. O processo de imigração de jovens de comunidades africanas em busca de estudos superiores em instituições brasileiras vem acontecendo há quase seis décadas, fator que motiva a criação de comunidades africanas em grandes cidades do país, como João Pessoa, Fortaleza, São Paulo, Rio de Janeiro, Curitiba e Porto Alegre (MENDONÇA, 2017).

Nesta categoria foram analisadas as razões pelas quais jovens migrantes escolheram o Brasil como destino, suas expectativas devido a uma imagem previamente construída no seu país de origem e experiências reais que tiveram no Brasil ao realizar o processo de migração. Estes estudantes acreditam que o Brasil possui um custo de vida mais baixo se comparado a outros, como EUA, Portugal e Austrália, por exemplo. Além disso, as especificidades sociais, históricas, educacionais, econômicas e culturais geram laços de amizade que unem o Brasil com os países do continente africano (SUBUHANA, 2009). Mendes (2012) e Subuhana (2009) exploram também os aspectos atrativos associados à imagem veiculada pela por agências de turismo do Brasil e pela mídia brasileira nos países africanos. As heranças africanas e portuguesas proporcionam a aproximação entre os mais diversos ambientes culturais pertencentes aos Países Africanos de Língua Oficial Portuguesa (PALOP) e o Brasil.

Os jovens africanos relatam sentir o contraste com toda a imagem que os motivou a estarem aqui, ao desembarcarem em São Paulo, a maior cidade do Brasil. Não podemos esquecer que a própria sociedade brasileira insiste no discurso de país multicultural, no qual há harmonia entre pessoas de diferentes origens, o que não condiz com a hierarquia social que atravessa as classes, especialmente os grupos historicamente vulnerabilizados (LIMA, 2017). A presença desses jovens em uma Universidade Brasileira traz a possibilidade de se experimentar o diverso no cotidiano desta Universidade, constituindo as relações que vão se estabelecendo ao longo dos anos da graduação, onde os encontros se dão de modo intercultural, diverso e diferente. Segundo Nhaga (2013), nesses deslocamentos está também o intercâmbio de valores, em que ideias sobre determinados fatos e acontecimentos passam a ser criadas e recriadas.

Esses fatores podem ser observados no desejo de conhecer um país que geralmente se apresenta alegre, divertido, com pessoas simpáticas, conforme os jovens africanos revelam em suas falas. Envolvidos por imagens preconcebidas sobre o seu futuro nos próximos anos 
(período da graduação), as informações transmitidas pela mídia brasileira, que vincula constantemente a ideia de que no Brasil se vive uma pacificação racial (SILVA; ROSEMBERG, 2008), reflete certos lugares de estereotipagem e objetificação destinados aos negros, principalmente relacionadas ao futebol e ao carnaval. Outro exemplo dessa objetificação é a imagem da mulher negra brasileira metaforizada na figura da mulata que ocorre pacificamente no país (KALY, 2001). Diferentes emoções vão compondo esse cenário no qual o Brasil imaginário se depara com o Brasil real, causando grande impacto sobre os jovens e seu futuro. E é com esse contraste que eles iniciam sua grande jornada rumo à realização de seus sonhos, às descobertas de uma nova cultura, de um novo povo, com hábitos e costumes diferentes dos deles.

\section{O preconceito e suas diferentes tonalidades}

A partir do grupo analisado foi possível observar a complexidade da questão do preconceito nas narrativas dos jovens. Alguns disseram não sentir o preconceito, outros disseram que sentem, mas que não sofrem impacto em sua migração, outros ainda relacionaram o preconceito com a falta de informação sobre o Continente Africano. Em relação aos que disseram não sentir, os discursos mostraram que foi como se esses jovens não tivessem experimentado a exclusão e nem o preconceito durante suas experiências. Desse modo, é possível pensar que a matriz do preconceito, nesses casos, não teria sido construída dentro deles e, por isso, não denominam ou significam o que muitas vezes chamamos de preconceito como tal.

Já em relação aos que disseram sentir, foi possível observar que muitos destes estudantes migrantes temporários percebem, ainda hoje, século XXI, as questões do preconceito racial como temas vivenciados por brasileiros todo o tempo, de maneira explícita ou não. Esse fenômeno compõe a migração internacional temporária desses jovens provenientes do Continente Africano que, por muitas vezes, são julgados por sua negritude (FIGUEIREDO, 2013). A questão racial no Brasil relaciona-se intrinsecamente às questões sociais e econômicas, sendo esses dois fatores estruturantes primordiais para a geração das grandes desigualdades do país e da pobreza. Segundo Teixeira (2010), o "racismo à brasileira" trata sobre discriminar de forma sutil sem parecer que está discriminando. É próprio da sociedade brasileira o preconceito de "marca" onde quanto mais evidente o fenótipo, quanto mais a aparência for negra, maior será o preconceito (MÜLLER et al., 2009). 
Os indivíduos que pertencem aos grupos minoritários (TAJFEL, 1982) inseridos em sociedades que possuem sua estrutura baseadas em desigualdades de poder estão consequentemente à mercê de múltiplas formas de exclusão. Tais conflitos refletem na identidade social, nas relações e formação dos sujeitos. Dessa forma, os relacionamentos acabam sendo estabelecidos como consequência de pertencer a um ou outros grupos, através de processos de exclusão/inclusão social (SAWAIA, 2008). As relações de poder e dominação entre diferentes grupos que compartilham o mesmo lugar social, atravessadas por práticas de discriminação e exclusão, repercutem em sofrimento, de diferentes formas.

A dimensão individualizante do problema do preconceito vem sendo superada pela vertente sociológica, que o direciona para uma compreensão igualmente mais ampla e que possui como referenciais as relações entre os processos dialéticos de exclusão e de inclusão e os grupos sociais (SAWAIA, 2008). Por sua vez, Lima e Vala (2004), identificam o racismo como um processo de hierarquização, afastamento e discriminação contra um indivíduo ou toda uma categoria social que é definida como diferente a partir de alguma marca física externa, seja esta real ou imaginária, a qual é ressignificada como uma marca cultural definidora de padrões de comportamento. Muller et al (2009) afirmam que o preconceito contra a população negra no país se origina num processo histórico que pretendeu manter os negros brasileiros como cidadãos de segunda categoria. Tal processo se deu através da difusão de centenas de imagens negativas contra as pessoas. A marca física externa, no caso do racismo brasileiro, são os traços afrodescendentes, como o formato do rosto, a cor da pele, e o estilo de cabelo. A marca cultural, além dos diferentes estereótipos estabelecidos como parte do ambiente sociocultural, pode ser identificada pelas diferentes manifestações populares associadas à ideia de raça e classe.

De acordo com Kaly (2001) e Subuhana (2005), o preconceito racial é a principal causa do mal-estar em terras brasileiras; e ser universitário e estrangeiro atenua a experiência negativa da discriminação racial. Langa (2014) mostrou que estudantes africanos, no seu cotidiano, percebem a dificuldade dos brasileiros em chamá-los pelos nomes próprios, substituindo-os por outras categorias de apelidos. O tratamento recebido pelos estudantes africanos na sociedade brasileira são os mesmos tratamentos direcionados à população negra local, estereótipos relacionados à periculosidade, marginalidade, pobreza, ignorância, dentre outros (KALY, 2001). A associação entre a cor da pele e pobreza nutre o preconceito contra estudantes estrangeiros que vivem no Brasil e geram diferentes situações constrangedoras de racismo (SUBUHANA, 2005). Para Lima e Vala (2004, p. 407), o racismo à brasileira "nada tem de cordial, pois implica num cenário sinistro de discriminação e exclusão". Tcham (2012, 
p. 50) afirma que "de um modo geral, o estudante preto africano no Brasil, independentemente de status social em seu país de origem, é quase sempre colocado nas camadas sociais mais inferiorizadas e humilhadas da sociedade”. Sendo assim, é possível observar que as diferenças raciais ainda são tratadas em nosso país e em nossas universidades não apenas como diferenças, e sim com desigualdades, implicando em um cenário de exclusão no qual as pessoas possuem pouca competência cultural para lidar com o diferente.

\section{Marcas impressas pela migração}

A migração para fins de qualificação acadêmica vem ganhando notoriedade dentro das pesquisas acadêmicas pelo fato de ser cada vez mais frequente, multifacetada e complexa (BROOKS; WATERS, 2011; OLWIG; VALENTIN, 2015). Para Kaly (2001), desde o século XIX o Brasil possui a tradição de receber jovens de países africanos nas instituições de ensino brasileiras. Segundo o autor, os filhos e filhas de alguns dignitários angolanos e moçambicanos eram enviados para serem educados nas escolas do Rio de Janeiro. Os fluxos entre África e Brasil podem ser analisados a partir de seus aspectos histórico que estão diretamente relacionados aos processos coloniais e pós-coloniais vivenciados por ambos os povos. A partir das narrativas dos jovens em relação à experiência de migração internacional temporária é possível perceber que esse fato pode ser um transformador na vida, não só deles, mas também de famílias, comunidades, de um povo e até de uma nação. Entende-se que o sujeito que migra não é movido apenas por questões econômicas, típicas da migração tradicional, mas também por fatores objetivos e subjetivos relacionados com a experiência migratória e com a realidade com que se deparam nos países de acolhimento (GUSMÃO, 2012). A fala dos estudantes demonstra dificuldades que compõem um cenário de luta, desafios e conquistas, não só de maneira pessoal e singular, mas também porque eles representam um povo em busca de melhores possibilidades de estudo e oportunidades. Tal fato envolve "um estar aqui (Brasil) e um ser de lá (África)". Envolve ser africano, estrangeiro e negro "fora de lugar" e se dão como reflexos das relações em processo, estabelecidas no contexto social de acolhida e que possui uma dimensão contraditória e conflitiva que, como aponta Silva (2005), exige ser compreendida posto que se associe a perdas e separações, mas também, a reencontros, voltas e reconstruções culturais. Trata-se de um povo que acredita ser possível transformar sonhos em realidade e transformar uma história, sendo a migração uma experiência que coloca em relevo a memória. 
Segundo Danticat (1998) as experiências e memórias individuais são também sociais e coletivas, dado que através do ato de recordar que um indivíduo compartilha alguns momentos de sua experiência do passado. Acredita-se que a partir das experiências familiares é que se constrói grande parte da memória e que estas experiências quase sempre contemplam narrativas sobre seu país de origem. Sarlo (2007) aponta que a memória não deixa dúvidas que as suas fontes e suas narrativas são lembranças de suas experiências, "memória que pode ter sido tomada por empréstimo de familiares e que a parte mais substancial vem de histórias contadas ao longo dos anos pela mãe e pelo pai ou parentes como um todo". Essas memórias são recriadas em contextos de migrações e costumam forçar o olhar de si para frente e para trás ao mesmo tempo, mantendo desta forma sempre acesa a complexa decisão de ficar ou voltar.

\section{Considerações finais}

Percebemos que os estudantes provenientes de diferentes países da África não se pautam por uma única identidade, cultura e tradição. Compreende-se que "o que são" e "o que expressam" são constituídos não só de relações históricas concretas, do passado e do presente em suas diversas e diferentes nações, mas também das relações que constroem no cotidiano de suas vidas, no aqui e agora de sua existência e, de modo particular, no interior da Universidade e do processo educativo. Foi possível observar, a partir do que foi levantado neste estudo, que a imigração acarreta uma série de impactos na vida dos jovens estudantes africanos e influencia na maneira como esses significam suas experiências de migração, permeando questões como a dificuldade de adaptação, o desempenho acadêmico e o isolamento (GUSMÃO, 2011).

Com base nos discursos dos alunos, ficou explícito que questões relacionadas ao preconceito, às experiências migratórias e as vivências no Brasil, são fatores que atravessaram a vida desses jovens e permearam suas permanências dentro das universidades Brasileiras. As categorias que foram levantadas são indicadores de como as questões relacionadas à diversidade vem sendo tratada por nossa sociedade atualmente. Sendo assim, é evidente a necessidade de as Universidades possuírem melhor preparo para com a recepção e ambientação desses alunos, a fim de minimizar as desigualdades de oportunidades e aumentando as possibilidades de um diálogo intercultural. 


\section{REFERÊNCIAS}

AMARAL, J. B. Atravessando o Atlântico: o Programa Estudante Convênio de Graduação e a cooperação educacional brasileira. Brasília-DF. 2013. 145 p. Dissertação (Mestrado Acadêmico em Desenvolvimento, Sociedade e Cooperação) - Centro de Estudos Avançados (CEAM), Universidade de Brasília (UnB), Brasília, DF, 2013.

BARRETO, L.; COUTINHO, M.; RIBEIRO, C. Qualidade de vida no contexto migratório: um estudo com imigrantes africanos residentes em João Pessoa-PB, Brasil. MudançasPsicologia da Saúde, São Bernardo do Campo, v. 17, n. 2, p. 116-122, jul./dez. 2009.

BROOKS, R.; WATERS, J. Student mobilities, migration and the internationalization of higher education. London: Palgrave Macmillan, 2011.

FIGUEIREDO, D. M. Diálogos interculturais dentro de uma universidade brasileira. 2013. 166 f. Dissertação (Doutorado em Psicologia) - Pontifícia Universidade Católica de São Paulo, São Paulo, 2013.

FIGUEIREDO, J. M. Fluxos migratórios e cooperação para o desenvolvimento: realidades compatíveis no contexto europeu? Lisboa: Observatório da Imigração, ACIME, 2005. v. 3.

GUSMÃO, N. M. "Na Terra do Outro": a presença de invisibilidade de estudantes africanos no Brasil, hoje. Dimensões, Vitória, v. 26, n. 1, p. 191-204, 2011.

GUSMÃO, N. M. África, Portugal e Brasil: um novo Triângulo das Bermudas? Cadernos CERU, Campinas, v. 23, n. 2, p. 51-62, dez. 2012. DOI: doi.org/10.11606/issn.25952536.v23i2p51-62

KALY, A. P. O Ser Preto africano no "paraíso terrestre" brasileiro: Um sociólogo senegalês no Brasil. Lusotopie, Rio de Janeiro, v. 8, n. 1, p. 105-121, out. 2001.

LANGA, E. N. B. Diáspora Africana no Ceará - Representações sobre as festas e as interações afetivo-sexuais de estudantes africano(a)s em Fortaleza. Revista Lusófona de Estudos Culturais, Porto, v. 2, n. 1, p. 102-122, jun. 2014.

LIMA, L. S; FEITOSA, G. G. Sair da áfrica para estudar no Brasil: fluxos em discussão.

Psicol. Soc., Belo Horizonte, v. 29, e162231, ago. 2017.

LIMA, M.; VALA, J. As Novas Formas de Expressão do Preconceito e do Racismo. Estudos de Psicologia, Natal, v. 9, n. 3, p. 401-411, dez. 2004.

MALOMANO, B.; FONSECA, D. J.; BADI, M. K. Diáspora africana e migração na era da globalização: experiências de refúgio, estudo, trabalho. Curitiba, PR: CRV, 2015.

MENDES, C. F. Uma vitrine do Brasil: telenovelas brasileiras entre estudantes africanos. 2012. 190 f. Dissertação (Mestrado em Antropologia Social) - Universidade de Brasília, Brasília, DF, 2012.

MÜLLER, M. et al. Educação e diferenças: os desafios da Lei 10.639/03. Cuiabá, MG: Ed. UFMT, 2009. 
NHAGA, B. Fluxos migratórios dos estudantes africanos para o Brasil: sistema de integração de estudantes africanos nas universidades públicas do Nordeste (UFCG, UFPB e UFPE). 2013. 156 f. Dissertação (Mestrado em Ciências Sociais) - Universidade Federal de Campina Grande, Campina Grande, PB, 2013.

OLWIG, K. F.; VALENTIM, K. Mobility, Education and Life Trajectories: New and Old Migratory Pathways. Identities: Global Studies in Culture and Power, v 22. n. 3, p. 247 $257,2015$.

PEC-G. Programa de Estudantes-Convênio de Graduação. Divisões de temas educacionais e língua portuguesa (DELP). Disponível em: http://www.dce.mre.gov.br/PEC/PECG.php. Acesso em: 22 maio 2020.

SARLO, B. Tempo passado: cultura da memória e guinada subjetiva. São Paulo, SP: Companhia das Letras, 2007.

SAWAIA, B. As artimanhas da exclusão. Petrópolis, RJ: Vozes, 2008.

SILVA, M. M. Contribuições metodológicas para análise das migrações. In: DEMARTINE, Z. B. F.; TRUZZI, O. (org.). Estudos migratórios, perspectivas metodológicas. São Carlos, SP, 2005.

SILVA, P.; ROSEMBERG, F. Brasil: lugares de negros e brancos na mídia. In: DIJK, T. A. V. (org.). Racismo e Discurso na América Latina. São Paulo, SP: Contexto, 2008. p. 74117.

SUBUHANA, C. A experiência sociocultural de universitários da África Lusófona no Brasil: entremeando histórias. Pro-Posições, Campinas, v. 20, n. 1, p. 103-126, abr. 2009.

SUBUHANA, C. Estudar no Brasil: imigração temporária de estudantes moçambicanos do Rio de Janeiro. 2005. 156 f. Dissertação (Doutorado em Serviço Social) - Universidade Federal do Rio de Janeiro, Rio de Janeiro, RJ, 2005.

TAJFEL, H. Grupos humanos e categorias sociais. Lisboa, Portugal: Livros Horizonte, 1982.

TCHAM, I. A África fora de casa: sociabilidade, trânsito e conexões entre os estudantes africanos no Brasil. 2012. Dissertação (Mestrado em Antropologia) - Universidade Federal de Pernambuco, Recife, PE. 2012.

TEIXEIRA, M. Relações raciais na sociedade brasileira. 2. ed. Cuiabá, MG: UAB/EdUFMT, 2010. 


\section{Como referenciar este artigo}

FIGUEIREDO, D. M.; HORTA, A. L. M.; MACEDO, R. M. S. A desigualdade sentida na migração de estudantes universitários provenientes do continente africano. Doxa: Rev. Bras. Psico. E Educ., Araraquara, v. 22, n. 00, e021014, 2021. e-ISSN: 2594-8385. DOI: https://doi.org/10.30715/doxa.v22i00.15364

Submetido em: 25/07/2021

Revisões requeridas em: 17/08/2021

Aprovado em: 13/09/2021

Publicado em: 01/10/2021 